\title{
ERRATUM
}

\section{Erratum to: Callus induction and regeneration in Wolffia arrhiza (L.) Horkel ex Wimm}

\author{
Pavel Khvatkov • Mariya Chernobrovkina • \\ Anna Okuneva $\cdot$ Anastasiya Shvedova $\cdot$ \\ Inna Chaban $\cdot$ Sergey Dolgov
}

Published online: 17 September 2014

(C) Springer Science+Business Media Dordrecht 2014

\section{Erratum to: Plant Cell Tiss Organ Cult \\ DOI 10.1007/s11240-014-0603-4}

The Acknowledgments section was omitted from the original publication. It is included below.

\begin{abstract}
Acknowledgments The work was supported by grant of the Ministry of Education and Science of the Russian Federation (The government contract No. 14.B25.31.0027).
\end{abstract}

The online version of the original article can be found under doi:10. 1007/s11240-014-0603-4.

P. Khvatkov $(\bowtie) \cdot$ M. Chernobrovkina $\cdot$ A. Okuneva .

A. Shvedova $\cdot$ I. Chaban $\cdot$ S. Dolgov

All-Russia Research Institute of Agricultural Biotechnology,

Moscow, Russia

e-mail: khvatkov1987@gmail.com

P. Khvatkov · M. Chernobrovkina - A. Shvedova - S. Dolgov

Branch of Shemyakin and Ovchinnikov Institute of Bioorganic

Chemistry, Puschino, Russia 